\title{
Adsorption Phenomenon of Arundinaria alpina Stem-Based Activated Carbon for the Removal of Lead from Aqueous Solution
}

\author{
Yosef Asrat $\mathbb{D}^{1},{ }^{1}$ Amare Tiruneh Adugna $\mathbb{D},{ }^{1,2}$ M. Kamaraj $\mathbb{D},^{2,3}$ \\ and Surafel Mustefa Beyan (iD) \\ ${ }^{1}$ Department of Environmental Engineering, College of Biological and Chemical Engineering, \\ Addis Ababa Science and Technology University, P. O. Box 16417, Addis Ababa, Ethiopia \\ ${ }^{2}$ Bioprocess and Biotechnology Center of Excellence, Addis Ababa Science and Technology University, \\ Addis Ababa 16417, Ethiopia \\ ${ }^{3}$ Department of Biotechnology, College of Biological and Chemical Engineering, Addis Ababa Science and Technology University, \\ Addis Ababa 16417, Ethiopia \\ ${ }^{4}$ School of Chemical Engineering, Jimma Institute of Technology, Jimma University, Jimma, P. O. Box 387, Ethiopia
}

Correspondence should be addressed to Amare Tiruneh Adugna; amardugna@yahoo.com

Received 11 February 2021; Accepted 8 June 2021; Published 16 June 2021

Academic Editor: Ibrahim H. Alsohaimi

Copyright (c) 2021 Yosef Asrat et al. This is an open access article distributed under the Creative Commons Attribution License, which permits unrestricted use, distribution, and reproduction in any medium, provided the original work is properly cited.

\begin{abstract}
In this study, activated carbon was prepared from locally available bamboo (Arundinaria alpina) in Ethiopia to remove $\mathrm{Pb}$ (II) from wastewater. Various effects such as solution $\mathrm{pH}$, initial $\mathrm{Pb}$ (II) ion concentration, and adsorbent dose were investigated and accordingly discussed, and the process was carried out on a batch adsorption base. Dried Arundinaria alpina stem was activated with potassium hydroxide $(\mathrm{KOH})$ at a ratio of $1: 1(\mathrm{w} / \mathrm{v})$ and carbonized in a furnace at three temperature ranges $\left(500^{\circ} \mathrm{C}, 600^{\circ} \mathrm{C}\right.$, and $700^{\circ} \mathrm{C}$ ) for $3 \mathrm{~h}$. The physicochemical of Arundinaria alpina stem activated carbon (AASAC) was investigated and the resultant of $500^{\circ} \mathrm{C}$ treatment setup is found as ideal in terms of yield $(40.6 \mathrm{~g})$, ash $(3.5 \%)$, porosity $(0.704 \%)$, moisture (7.7\%), and iodine number $(814.69 \mathrm{mg} / \mathrm{g})$. The further characterization of ideal AASAC was carried out by scanning electron microscopy (SEM), $\mathrm{X}$-ray diffraction (XRD) spectroscopy, and Fourier transform infra-red (FTIR). The optimum $\mathrm{Pb}$ (II) removal efficiency of AASAC was $99.8 \%$ at $\mathrm{pH} 5$ in a synthetic solution, but the efficiency declined to $60.42 \%$ on real industrial wastewater due to the presence of its mixed pollutant nature. Freundlich isotherm model is more favorable than Langmuir with a high correlation coefficient $\left(R^{2}\right.$ 0.9496) for $\mathrm{Pb}$ (II) adsorption. The study revealed that AASAC has a potential adsorption efficiency to remove the $\mathrm{Pb}$ (II) ion from the aqueous solution which is also recommended as an adsorbent for real industry wastewater treatment.
\end{abstract}

\section{Introduction}

Heavy metals pollution has been a major concern globally. Sources of heavy metal pollution come from discharges of various industries such as petroleum refining, pesticides, smelting, mining, electroplating, tanning, glass, herbicides, and ceramic manufacturing industries [1]. $\mathrm{Pb}$ (II) is considered to be an extremely toxic metal without known biological function and higher concentrations; it can endorse poisoning and has a hazardous nature because it cannot be degraded or destroyed and tend to bioaccumulate $[2,3]$. It possesses risks not only to humans but also to animals and plants because of its severe toxic effects, and it has been the main reason behind the number of afflictions $[2,4]$. Different techniques have been employed to remove the lead ions from effluent solutions, for instance, chitosan, the biomass of microbial, coagulation, ion exchange, flotation, sedimentation, composite material, solvent extraction, membrane filtration, evaporation, and reverse osmosis [2]. But still, they have many limitations; for instance, chitosan has poor chemical resistance as well as thermal and mechanical properties [5]. Although microbial adsorbents are environmentally friendly compared to the conventional method, they have high limitations such as incomplete metal ions removal, high energy consumption, a large requirement of nutrients, and generations of waste products mostly toxic 
byproducts [6]. Among those methods, adsorption using agrobased activated carbon is widely used due to its high efficacy, being ecofriendly, simplicity, and cost-effectiveness $[2,7]$. The characteristics features of the adsorbent layout are the major factor for the effective adsorption of metal ions from the solution. Thus, many researchers are looking at different agrowaste and agromaterials for the preparation of activated carbon that can be used as adsorbents for the removal of heavy metal from industrial effluents or/and other wastewater environments. Consequently, novel agrobased activated carbon for the absorption of metal ions with high removal efficiency and high rate of adsorption is of great concern. This study is an attempt to investigate the Ethiopian bamboo-based activated carbon as an alternative option for lead removal. In Ethiopia, the natural bamboo forest has been estimated at around 1 million hectares which is the largest in the African continent accounting for $67 \%$ within the continent and $7 \%$ of the world total $[8,9]$. It produces an average annual stem increment of 8.5-10 tonnes $(t)$ of oven-dry matter per ha and possible to harvest about 3 mills t yr- 1 of oven-dry biomass on a sustainable basis from 1 mill. ha of bamboo in Ethiopia, assuming selective felling of culms 3 or more years of age. This could be used to supply part of the woodwork, pulp, furniture, construction, and energy requirements of the nation $[8,9]$. The demand for activated carbon is increasing owing to the increased utility of the carbon material in pollution control. As the applications of activated carbon are immense, the gap between demand and supply is ever widening. Exploring effective and low-cost activated carbon may contribute to environmental sustainability and offer benefits for future commercial applications. As discussed in detail in this paragraph, the availability of bamboo represents the feedstock to the activated carbon plant; thus, the raw material is very cheap. Plant resources are presently getting consideration as raw materials for water pollution treatment due to their availability and low cost $[7,10]$.

Hence, the objective of the study mainly revolves around the production of activated carbon from Arundinaria alpina bamboo as a locally abundant material and assessing its adsorption performance in $\mathrm{Pb}$ (II) removal in different experimental conditions. Furthermore, the study was designed for the investigation of process parameters, namely, solution $\mathrm{pH}$, initial $\mathrm{Pb}$ (II) concentration, and adsorbent dose. Moreover, experimental figures were subjected to kinetics and thermodynamical analysis for the investigation of removal rates of $\mathrm{Pb}$ (II) from the solution.

\section{Materials and Methods}

2.1. Collection and Preparation of Plant Biomass. The Arundinaria alpina bamboo used in this work was obtained from southwest Ethiopia (Tepi, District of Yeki), located in lat/long $7^{\circ} 3^{\prime} \mathrm{N}, 35^{\circ} 18^{\prime} \mathrm{E}$ with an altitude of $1700-2500 \mathrm{~m}$ and the total annual rainfall $1678 \mathrm{~mm}$ in a temperature of $30^{\circ} \mathrm{C}$ and a minimum of $15^{\circ} \mathrm{C}$. The collected bamboo stems were cut into pieces and grained with $1.5-2 \mathrm{~cm}$ size for the production of powdered activated carbon. The chopped bamboo was washed by tap water followed by distilled water to remove dirt matter on the surface of the bamboo stem and, then, dried in the oven at $105^{\circ} \mathrm{C} / 24 \mathrm{~h}$ for removing the moisture. Then, the dried samples were impregnated with potassium hydroxide pellets in a $1: 1$ ratio as an activating agent and the mixture was kept for $4 \mathrm{~h}$ and dried at $15^{\circ} \mathrm{C} / 12 \mathrm{~h}$ [11].

2.2. Carbonization for the Development of Adsorbent. The impregnated dried sample is carbonized in a Muffle Furnace (MF 106, NUVE) at three different temperatures of $500^{\circ} \mathrm{C}$, $600^{\circ} \mathrm{C}$, and $700^{\circ} \mathrm{C}$ for $3 \mathrm{~h} \mathrm{[12].} \mathrm{The} \mathrm{obtained} \mathrm{carbon} \mathrm{was}$ cooled for $24 \mathrm{~h}$ in a dissector and repeatedly washed with $0.1 \mathrm{M} \mathrm{HCl}$ and distilled water until the washing was free from the base medium; it must be down to neutral media ( $\mathrm{pH}$ H183141 Romania). The dried carbon samples were crushed using a mortar and pestle to obtain the desired particle size (sieve size $125 \mu \mathrm{m}$ model IC-205/EV, Italy). The resultant materials are designated as AASAC1, AASAC2, and AASAC3, based on the temperature setup as $500^{\circ} \mathrm{C}$, $600^{\circ} \mathrm{C}$, and $700^{\circ} \mathrm{C}$, respectively.

2.3. Characterization of AASAC. The physical analysis (moisture, ash content, volatile matter, specific gravity, and porosity of the AASAC) was conducted according to an American Standard Testing Method (ASTM) [13-16]. The ideal AASAC samples will be further characterized by analytical techniques such as SEM, XRD, and FTIR. SEM analysis was carried to capture the morphological structure of AASAC (HV/20.0 KV), model INSPECT F 50, FIY USA; FTIR (model IRAffinity-1S) was used to identify the functional group of bamboo activated carbon as follows: $2 \mathrm{mg}$ of AASAC powder with $300 \mathrm{mg}$ of anhydrous $\mathrm{KBr}$ (potassium bromide). The mixture was pressed under vacuum (hydraulic press Model-15) and the spectra were recorded between 4000 and $400 \mathrm{~cm}^{-1}$ for the evaluation of the surface composition of a material. The XRD (Miniflex 600 PxRD) was operated at $\mathrm{Cu} \mathrm{Ka} 40 \mathrm{kV} / 40 \mathrm{~mA}$ and a current of $15 \mathrm{~mA}$. The XRD patterns were collected with a scan rate of $4.2^{\circ} \mathrm{C} /$ min and the results were analyzed using standard software (Origin 2018 Version 9.55).

2.4. Batch Adsorption Experiments for Pb (II) Removal. A lead stock solution $\left(1000 \mathrm{mgL}^{-1}\right)$ was prepared by dissolving $1.5985 \mathrm{~g}$ of lead nitrate, $\mathrm{Pb}\left(\mathrm{NO}_{3}\right)_{2}$ in $1000 \mathrm{ml}$ of distilled water. Adsorption experiments were carried out at room temperature in batch mode with a volume of $250 \mathrm{ml}$. The adsorption experiment is performed at different operating conditions such as varied $\mathrm{pH}(3,5$, and 6), adsorbent dose ( $1 \mathrm{~g}, 1.5 \mathrm{~g}$, and $2 \mathrm{~g}$ ), and initial concentration $\left(50 \mathrm{mgL}^{-1}\right.$, $100 \mathrm{mgL}^{-1}$, and $\left.150 \mathrm{mgL}^{-1}\right)$. Microwave Plasma Atomic Emission Spectrometry (Agilent $4200 \mathrm{MP}$-AES) was used to measure the residual metal ion concentration. The percentage of $\mathrm{Pb}$ (II) removal was calculated in the following formula:

$$
\text { \%removal }=\frac{C_{0}-C_{t}}{C_{0}} * 100 \% \text {, }
$$


where $C_{0}=$ initial concentration of adsorbate and $C_{t}=$ final concentration of the adsorbate after the time $(t)$.

2.5. Isotherm Study for the Adsorption Experiment. The adsorption of $\mathrm{Pb}$ (II) by AASAC was assessed using Langmuir (Equation (2)) and Freundlich (Equation (3)) model as follows [17]:

$$
\frac{C_{e}}{q_{e}}=\frac{1}{q_{o} K_{L}}+\frac{C_{e}}{q_{o}},
$$

where $C_{e}$ is the equilibrium concentration of the adsorbate $\left(\mathrm{mg} \mathrm{L}^{-1}\right), q_{e}$ is the mass of solute adsorbed per unit mass of adsorbent, $q_{o}$ is a constant related to the adsorption capacity $\left(\mathrm{mg} \mathrm{g}^{-1}\right)$, and $K_{L}$ is the experimental constant.

$$
\log \left(q_{e}\right)=\log K_{L}+\frac{1}{n} \log C_{e},
$$

where $C_{e}$ is the equilibrium concentration of the adsorbate, $q_{e}$ is the mass of solute adsorbed per unit mass of adsorbent, and $k_{L}$ and $n$ are Freundlich constants representing the adsorption capacity of adsorbents and the intensity of the adsorption, respectively.

\subsection{Pb (II) Removal Efficiency of AASAC on Real Industrial} Wastewater. The wastewater is collected from the paint factory (located in the subcity of Nefas Silk-Lafto, Addis Ababa) from the equalization tank three times in five-day intervals. The adsorption experiment was carried out with the operational condition as follows at its original $\mathrm{pH}$, adsorbent dose $2 \mathrm{~g}$, and contact time 120 mins. The physicochemical characteristics $\left(\mathrm{pH}\right.$, turbidity, $\left.\mathrm{BOD}_{5}\right)$ of the effluent before and after adsorption were identified using ASTM $[18,19]$. The $\mathrm{Pb}$ (II) metal ion concentrations are measured using Microwave Plasma Atomic Emission Spectrometry (Agilent $4200 \mathrm{MP}-\mathrm{AES}$ ), and the adsorption efficiency (\%) is calculated as per (1).

\section{Results and Discussion}

3.1. Physicochemical Characterization of AASACs. The physicochemical characteristics of resultant bamboo stembased activated carbons are reported in Table 1. The moisture content $(7.70 \%$ to $6.20 \%)$ of AASAC directly influences the carbonization time and temperature. The ash of AASAC1 is its inorganic constituent, which is a white substance after bamboo carbon has burned completely; the ash percentage increased from $3.51 \%$ to $5.53 \%$. The low ash content would result in minimal effects of inorganic impurities on pore development during the activation process. Previous studies suggested that good quality carbon should be low in Ash but rich in carbon and volatile. Ash in activated carbon is undesirable and taken as an impurity. Ash could interfere with carbon adsorption through competitive adsorption and catalysis of adverse reactions [20]. At higher temperatures, organic substances became unstable as the heat provides energy to the molecules to break their bonding and linkages, and once these are broken.
The fact that decreasing tendency of porosity is observed due to carbonization temperature increase inversely correlated with that of percent porosity of AASAC's, and this can be ascribed as to the significant amount of volatile matter released during carbonization. Tar derived from the degradation of hemicellulose and lignin not only blocks the pore structure but also obstructs the formation and development of new pores resulting in low total pore volume and specific surface area [21]. The effect of iodine number adsorption of AASAC's results showed a reduction in the adsorptive capacity of carbon value. It is an indication of the beginning of structural deformation, and the activation temperature had a significant influence on the iodine number too. Increasing the temperature to $600^{\circ} \mathrm{C}$ and beyond will lead to the decrease of iodine number value [22]. Iodine number is a measure of activity level and the micropore content of the activated carbon; a higher number indicates a higher degree of activation [23].

3.2. Effects of Carbonization Temperature on Removal Efficiency. The temperature variance in the production of AASAC yielded the variation in removal efficiency from 97.9 to $77.5 \%$ for the solution containing initial metal ion concentration of $100 \mathrm{mg} \mathrm{L}^{-1}$, AASAC dose of $2 \mathrm{~g}$, and $\mathrm{pH} 5$ (Table 1). The reduction in removal might be due to a decrease in porosity of AASAC from $0.704 \%$ to $0.6926 \%$ up on increment with temperature which is due to the thermal influence and the lack of active site on the adsorbent; longer activation can lead to a higher weight loss of carbon precursor or formation of ash [24]. The maximum porosity occurs during the optimal activation process. When the process is carried out at elevated temperature, it depends upon whether the agricultural product or the naturally existing amorphous carbon structure has been distracted. The situation leads to unfavorable adsorption conditions or weak performance of the products [21]. Based on the primary characterization of three samples, the AASAC1 is found to be a better adsorbent. Hence the further instrumental characterizations and $\mathrm{Pb}$ (II) adsorption studies at varied parameters have proceeded with only AASAC1.

3.3. SEM Analysis of AASAC1. The surface texture and porosity of AASAC1 in a secondary electron image mode showed the presence of an organized pore region in the fibrovascular bundle wall (Figure 1(a)). The activated carbon surface has abundant pores characterized by thick pore walls and circular pores. The pores on the surface could be macropores which lead to the branching micropores in the interiors of the activated carbon [25]. Figure 1(b) shows the changes in some parts of the surface particles with native biosorbent which depicts that $\mathrm{Pb}$ (II) ion has deposited as aggregates in the AASAC1. The surface nature of the AASAC1 is highly supportive of the physical adsorption, which provides an active site to the positive contaminant, and the ion can easily enter at the existing pores, but the interaction may not be strong enough to separate the contaminant from the solution. 
TABle 1: Physicochemical and Pb (II) removal characteristics of AASAC.

\begin{tabular}{lccc}
\hline Parameters & & Activated carbon samples \\
& AASAC $1\left(500^{\circ} \mathrm{C}\right)$ & AASAC $1\left(600^{\circ} \mathrm{C}\right)$ & AASAC $1\left(700^{\circ} \mathrm{C}\right)$ \\
\hline Proximate analysis (\%) & & & 7.01 \\
Moisture & 7.7 & 4.73 & 6.20 \\
Ash & 3.5 & 38.04 & 5.53 \\
Yield & 40.6 & 22.27 & 36.01 \\
Volatile matter & 23.4 & 0.6962 & 21.07 \\
Porosity (\%) & 0.704 & 22.27 & 0.6926 \\
Volatile matter (\%) & 23.4 & 1.486 & 21.07 \\
Specific gravity (gm/cm3) & 1.470 & 86.3 & 1.550 \\
Pb (II) removal (\%) & 99.8 & & 77.5 \\
\hline
\end{tabular}

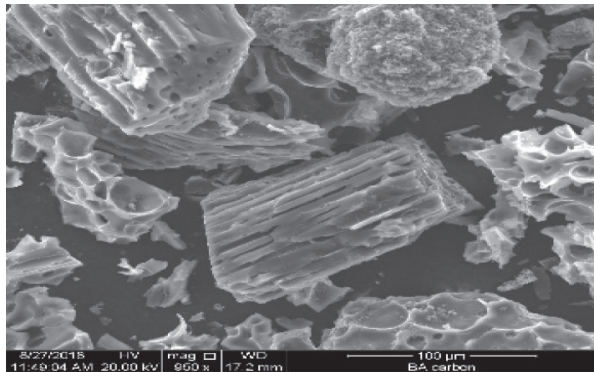

(a)

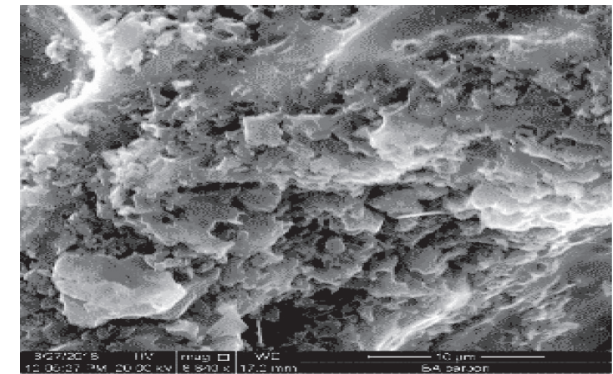

(b)

FIgURE 1: SEM micrograph of BMSAC1 (before (a) and after (b) adsorption).

3.4. FTIR Analysis of AASAC1. FTIR spectrum results revealed the presence of different surface functional groups of AASAC1 in Figure 2. Functional groups in the adsorbent are contributed significantly to enhance the adsorption efficiency of the activated carbon by surface complexation [26]. The assignment of peaks at specific wavenumbers is listed in Table 2. The band observed at $1630 \mathrm{~cm}^{-1}$ is assigned to $\mathrm{C}=\mathrm{C}$ bond (Alkane), and the bands 1315 and $1210 \mathrm{~cm}^{-1}$ are assigned to $\mathrm{C}-\mathrm{O}$ stretch (alcohols, ethers, acids, and esters) [27]. These peaks which correspond to different functional groups are possible sites for the adsorption of this metal ion by the adsorbents. The peak intensities indicate that especially the $\mathrm{OH}$ groups, the $\mathrm{C}-\mathrm{O}$ stretch of either alcohol, ethers, carboxylic acids or esters, the $\mathrm{N}-\mathrm{H}$ stretch of the primary or secondary amines, $\mathrm{N}-\mathrm{H}$ bend of the amine or amides, and the $\mathrm{C}=\mathrm{C}$ stretch of the alkenes may play a major role in the adsorption of $\mathrm{Pb}$ (II) from aqueous solution. These functional groups contain either $\pi$-electron which is electron rich in or lone pairs on nitrogen or oxygen, with which they can coordinate with the metal ion leading to adsorption [28]. Many wavenumbers of AASAC1 are found to differ after adsorption (Figure 2(b)) when compared to before adsorption, which is attributed to a shift during the adsorption process.

3.5. XRD Analysis of AASAC1. The X-ray diffraction was used to investigate the surface structure of locally produced AASAC1, based on the diffraction pattern; the crystalline and graphite structures in the matrix were analyzed. Figure 3 shows seven broad intense peaks around 35, 45, 50, 52, 69, and 72. The peak that forms at $2 \Theta=35$ degrees shifts to a low angle in the case of $\mathrm{KOH}$-activated AASAC1, which mean that their amorphous structures are strengthened. In other words, their graphitic microcrystalline is destroyed more severely, which may lead to the widening of pores because the walls are containing graphitic microcrystalline [29].

3.6. Effects of Solution $p H$ on the Adsorption Process. The removal efficiency greatly increased from $\mathrm{pH} 3(70.37 \%)$ to pH 5 (99.8) and then decreased slightly with pH 6 (90.8\%) (Figure 4(a)). These phenomena attribute to the interaction of the positive ion with the AASAC1 surface metal ion. At higher than 7 , the precipitation of $\mathrm{Pb}$ (II) ion takes place [30]. Such a trend can be explained based on a surface charge on the adsorbent and speciation of $\mathrm{Pb}$ (II) [17]. At low $\mathrm{pH}$, the surface of the adsorbent was surrounded by $\mathrm{H}^{+}$ions which could compete with $\mathrm{Pb}$ (II) ion surface adsorption sites, thereby preventing the $\mathrm{Pb}$ (II) ion from approaching the binding sites on the adsorbent. With the increase of $\mathrm{pH}$, some of the adsorption sites are deprotonated and $\mathrm{Pb}$ (II) ions are adsorbed along with $\mathrm{H}^{+}$ions, and when $\mathrm{pH}$ is higher than 5, competition between $\mathrm{H}^{+}$and $\mathrm{Pb}$ (II) ion for surface adsorption sites decreases. At the same time, the negative charge density on the carbon surface increases due to deprotonation of the $\mathrm{H}^{+}$ions containing sites, thereby improving the adsorption capacity towards $\mathrm{Pb}$ (II) ion [30]. Researchers also found an optimum $\mathrm{pH}$ obtained at 5.50 for removal of $\mathrm{Pb}$ (II) based on the sensitivity $[31,32]$. $\mathrm{pH}$ value significantly influences the adsorption behavior; it leads to 


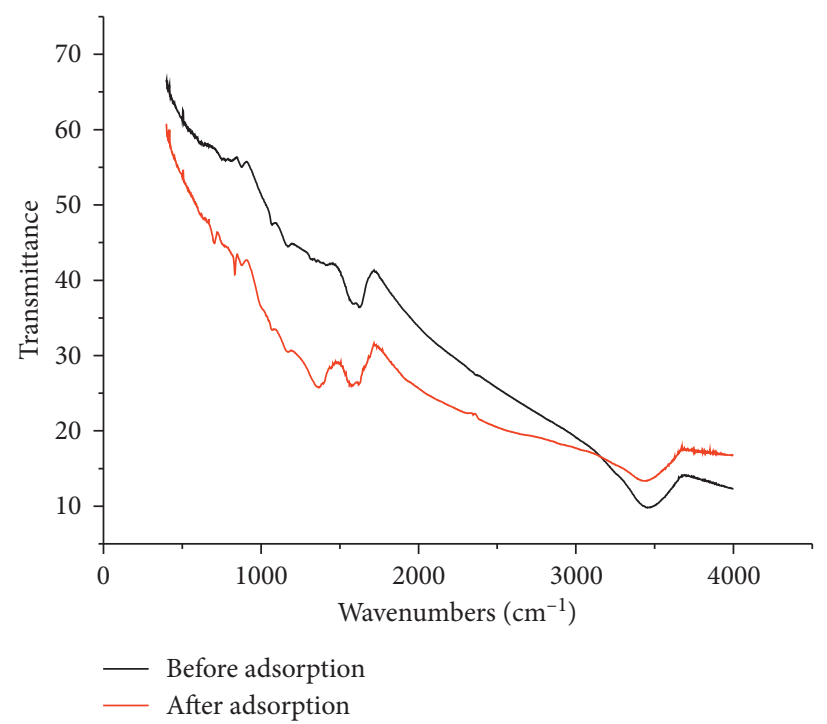

FIGURE 2: FTIR spectra for BMSAC1 (before (a) and after adsorption (b)).

TABLE 2: FTIR spectral characteristics of AASAC1 before and after adsorption.

\begin{tabular}{|c|c|c|}
\hline \multicolumn{2}{|c|}{ Wavenumber $\left(\mathrm{cm}^{-1}\right)$} & \multirow{2}{*}{ Assignment } \\
\hline Before & After & \\
\hline 3454 & 3384 & O-H stretching in a hydrogen bond \\
\hline 1612 & 1630 & $\mathrm{C}=\mathrm{C}$ alkane, $\mathrm{C}=\mathrm{O}$ \\
\hline 1315 & 1516 & $\mathrm{C}-\mathrm{C}=\mathrm{C}$ asymmetric stretch, $\mathrm{N}=\mathrm{O}$ stretch, $\mathrm{N}=\mathrm{O}$ bend \\
\hline 1167 & 1210 & $\mathrm{C}=\mathrm{O}$ stretch, $\mathrm{C}-\mathrm{O}$ alcoholic stretch, carboxylic acid, anhydrides \\
\hline 782 & 503 & Aromatic (out-of-plane band) \\
\hline
\end{tabular}

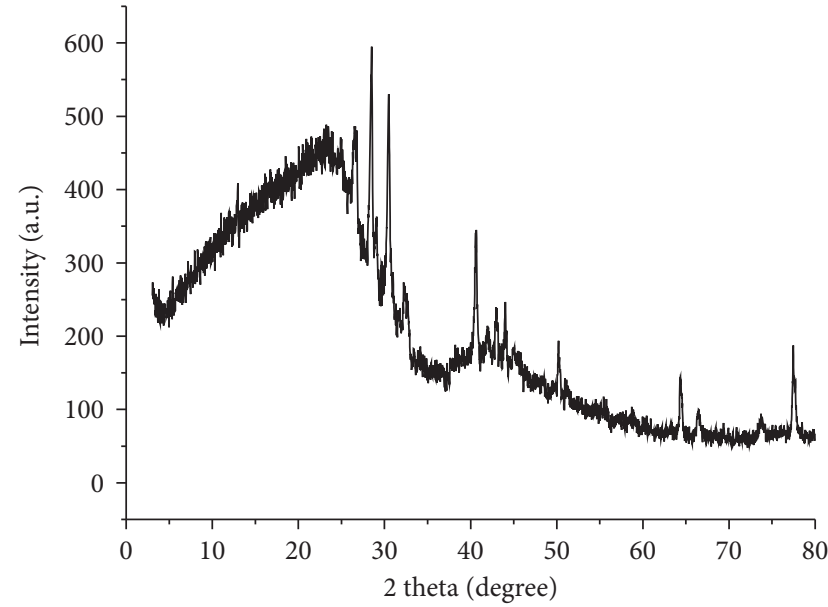

Figure 3: XRD analysis of BMSAC1.

precipitation of the metal which is very likely to occur in environments with high $\mathrm{pH}$ (above 7 ), in which there are also carbonates, sulfur, or phosphate with which it can react [33]. Also, above the $\mathrm{pH}$ neutral area, the $\mathrm{Pb}(\mathrm{II})$ adsorption is very low because of the precipitation matter [34].

\subsection{Effects of Initial Metal Ion Concentration on Adsorption.} The $\mathrm{Pb}$ (II) removal efficiency was observed optimum as $99.8 \%$ at $50 \mathrm{mg} \mathrm{L}^{-1}$ and found to be decreased as 98.2
(100 $\left.\mathrm{mg} \mathrm{L}^{-1}\right)$ and $94.2\left(150 \mathrm{mg} \mathrm{L}^{-1}\right)$ with the increment of $\mathrm{Pb}$ (II) ion concentration which increases the number of available molecules per binding sites of the adsorbent (Figure 4(b)). An increase in initial metal ion concentration enhances the interaction between the metal molecules and the surface of the adsorbent [35]. Meaning, it provides a driving force to overcome mass transfer resistance between the biosorbent and biosorption medium. The effect of initial concentration is more efficient at low $\mathrm{Pb}$ (II) concentration. This is because at low $\mathrm{Pb}$ (II) concentration, the ratio of the adsorption site to the total mean ions in the solution is high, and hence all the $\mathrm{Pb}$ (II) may interact with the adsorbent and finally be removed from the solution [30]. Concentration increases with a greater number of ions and the same charge to be adsorbed and compete for the same adsorption sites. This may cause to leave many ions without being adsorbed and to decrease the efficiency of removal upon increase of the concentration of $\mathrm{Pb}$ (II) ion. At higher initial solution concentration, the total available adsorption sites are limited, thus resulting in a decrease in the percentage of removal of metal ion [36].

3.8. Effects of AASAC1 Dose on Removal Efficiency of Pb (II). Determination of a suitable adsorbent dose is considered one of the important parameters to ensure optimal adsorption without losing adsorbents. The effect of the 


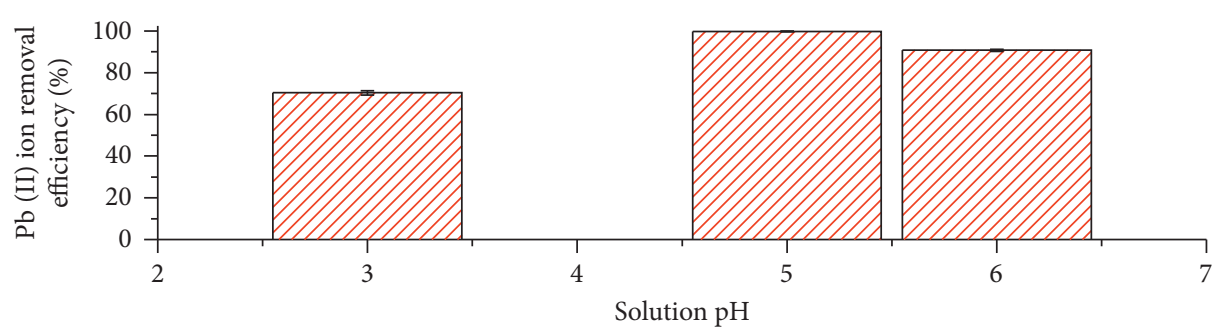

(a)

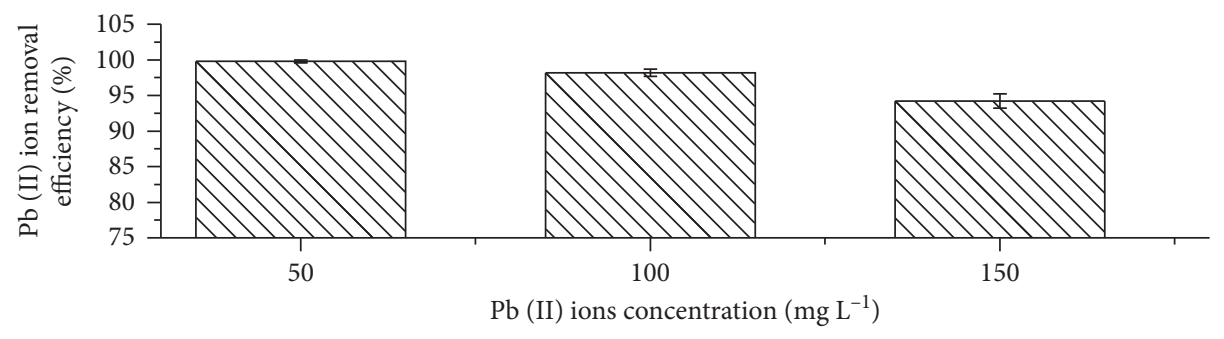

(b)

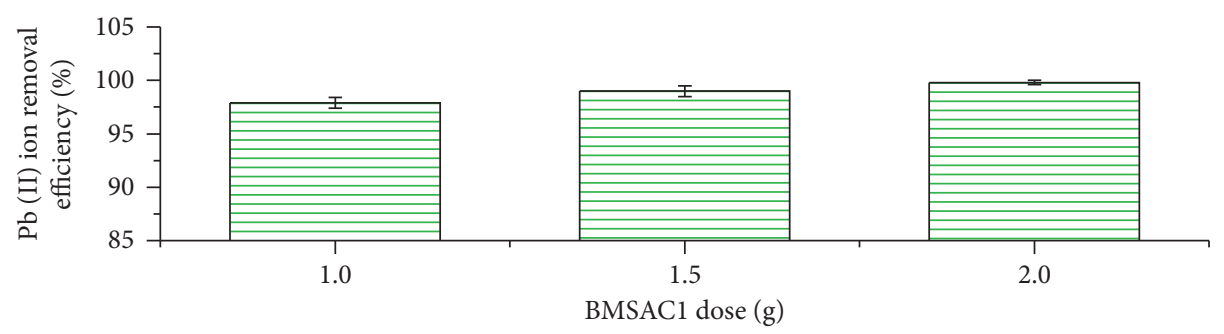

(c)

FIgURE 4: Effects of $\mathrm{pH}, \mathrm{Pb}$ (II) ion concentration and adsorbent dose on $\mathrm{Pb}$ (II) removal efficiency of BMSAC1 in a synthetic solution.

adsorbent dose is shown in this study as $97.9 \%$ removal efficiency for 1 and it raised to $99 \%$ for $1.5 \mathrm{~g}$ adsorbent dose; however, a slight increase was observed for the $2 \mathrm{~g}$ adsorbent dose (Figure 4(c)). The percentage of metal sorbed increases with an increase in adsorbent dose for the heavy metals [37]. Since the quantity of metal ion is constant, an increase in the amount of adsorbent above a quantity that can completely adsorb the available metal ion had no apparent effect on a further increase of percent adsorption [25]. The percentage removals of metal increase rapidly with an increase in the dose of the adsorbents due to the greater availability of the exchangeable sites or surface area [38].

3.9. Effect of $\mathrm{Pb}$ (II) Concentration, Dose, and $\mathrm{pH}$ versus Removal Efficiency (\%). The interaction of the three independent variables, initial $\mathrm{Pb}$ (II) ion concentration, and $\mathrm{pH}$ of the solution has indirect relationships, at each condition from $50 \mathrm{mg} \mathrm{L}^{-1}$ to $150 \mathrm{mg} \mathrm{L}^{-1}$, while there is a constant adsorbent dose (2 g), at lower $\mathrm{pH}$ (3) percent removal efficiency, whereas at low initial $\mathrm{Pb}$ (II) ion concentration, removal efficiency increases, while above $50 \mathrm{mg} \mathrm{L}^{-1}$ of initial concentration, the removal efficiency starts to decline, in Figure 5(a). Varying the independent variables that are $\mathrm{pH}$ and adsorbent dose while initial $\mathrm{Pb}$ (II) ion concentration is constant, both variables $\mathrm{pH}$ from (3 to 5 ) and adsorbent dose from $(1 \mathrm{~g}$ to $2 \mathrm{~g}$ ), it increases the removal efficiency of
AASAC1; however, in a certain $\mathrm{pH}>5$, it starts to slow the removal efficiency of AASAC1 (Figure 5(b)), and the reason for this has been discussed in the above section.

3.10. Equilibrium Sorption Study. Sorption studies describe the interaction of adsorbates with adsorbents and establish the equilibrium between the adsorbed metal ion and the residual metal ion in solution during the surface sorption. The plot in Figure 6(a) has an $R^{2}$ value of 0.9232 with a slope and intercepts value of 0.2091 , respectively. The Freundlich parameters $\left(K_{f}\right.$ and $n$ ) for adsorption of the $\mathrm{Pb}$ (II) ion into AASAC1 are determined from the slope and intercept values of the equilibrium data well fitted in this isotherm which means it had a greater $R^{2}$ value, indicating that sorption of $\mathrm{Pb}$ (II) metal ion studied adsorbents was favorable. The higher value of the coefficient of regression $R^{2}=0.9496$ was obtained (Figure 6(b)) for the adsorption of metal ion $\mathrm{Pb}$ (II) ion. It was clear that the adsorption of lead onto bambooactivated carbons derived from these adsorbents obeys the Freundlich isotherm model.

3.11. The Efficiency of AASAC1 for Real Industrial Wastewater. In conclusion, the experiment was carried out on real waste samples to check the viability of the adsorbent in the real wastewater. The paint industry wastewater treated with AASAC1 has shown a significant improvement in its 


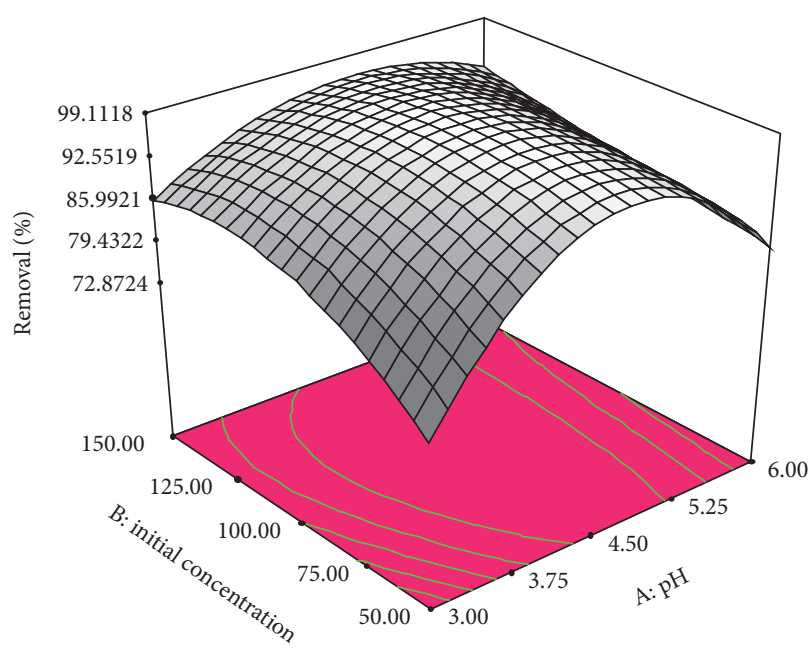

(a)

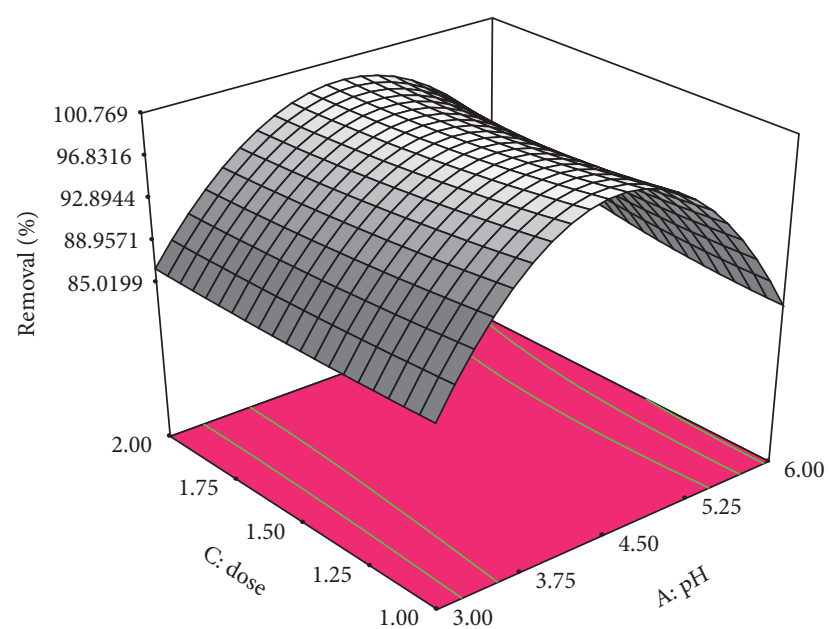

(b)

FIgURe 5: 3D plots for the effect of the combined factors on removal efficiency. $\mathrm{Pb}^{2+}$ concentration and $\mathrm{pH}$ on removal (a) and initial adsorbent dose and $\mathrm{pH}$ on removal (b).

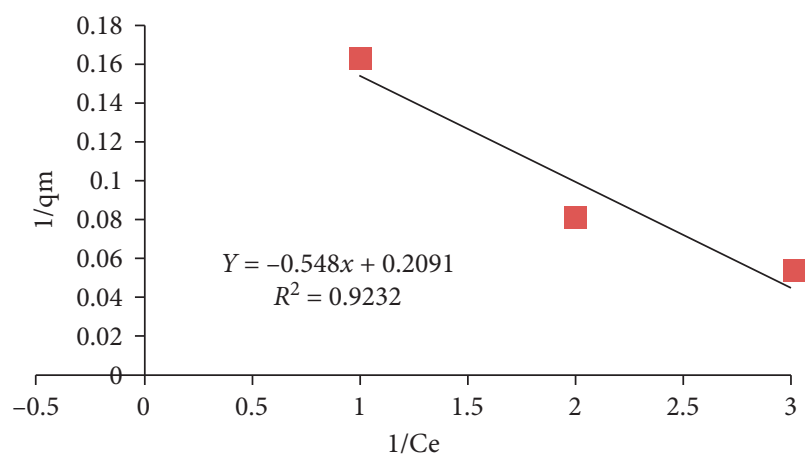

(a)

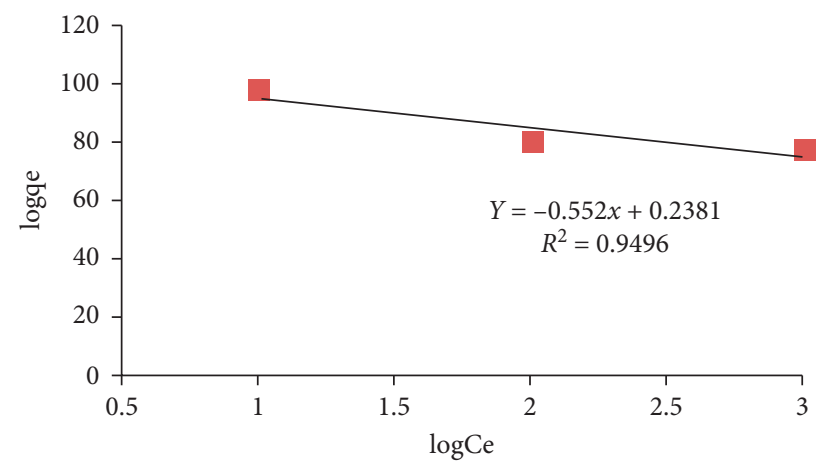

(b)

FIGURE 6: Langmuir (a) and Freundlich (b) adsorption isotherm for adsorption of $\mathrm{Pb}$ (II) on BMSAC (pH: 5, adsorbent dose: $2 \mathrm{~g}$ and contact time 120 mins).

TABLE 3: Real paint industry wastewater (untreated and treated) characteristics.

\begin{tabular}{lccc}
\hline Parameters & Unit & Untreated wastewater & Treated wastewater \\
\hline $\mathrm{pH}$ & $\mathrm{pH} \mathrm{unit}$ & 5.5 & 6.5 \\
Turbidity & $\mathrm{NUT}$ & 255 & 10 \\
$\mathrm{BOD}_{5}$ & $\mathrm{mg} \mathrm{L}^{-1}$ & 171 & 25 \\
$\mathrm{COD}$ & $\mathrm{mg} \mathrm{L}^{-1}$ & 2402 & 150 \\
$\mathrm{TSS}$ & $\mathrm{mg} \mathrm{L}^{-1}$ & 619 & 138 \\
$\mathrm{~Pb}(\mathrm{II})$ & $\mathrm{ppm}$ & 2.99 & 0.428 \\
\hline
\end{tabular}

physicochemical characteristics (Table 3). The wastewater initially contained $2.99 \mathrm{ppm}$ of $\mathrm{Pb}$ (II) metal ion which is reduced to $1.185 \mathrm{ppm}, \mathrm{pH}$ of the treated wastewater nearly 6.5 after adsorption with AASAC1. However, the removal efficiency of AASAC1 in synthetic aqueous solution (99.8\%) is declined to $60.42 \%$ in real industrial wastewater. This is due to the nature of synthetic wastewater containing individual ion, where the real wastewater containing mixed pollutant in the solution affected the removal efficiency by competing for one another to the adsorbent site.

\section{Conclusion}

This study concentrated on $\mathrm{Pb}$ (II) ion removal from aqueous solution using Ethiopian bamboo activated carbon with an extended application on real paint industry wastewater. The characterization of AASAC1 indicated its excellent capacity of removing $\mathrm{Pb}$ (II) from aqueous solution and average capacity in paint industry wastewater. Among the tested operational parameters conditions, the better range is found as $2 \mathrm{~g}$ adsorbent dosage, $200 \mathrm{rpm}$ agitation speed with the contact time of $120 \mathrm{~min}$, and the $\mathrm{pH} 5$. At lower temperature $500^{\circ} \mathrm{C}$ and more holding time ( $3 \mathrm{~h}$ ), it was observed that greater iodine values were recorded, the residual volatile matter was completely released, and more microporous structures have developed. Greater $R^{2}$ value indicated the sorption of $\mathrm{Pb}$ (II) ion into AASAC1 favorable to Freundlich isotherms. The study suggests that the 
AASAC1 mediated adsorption is effective in the removal of $\mathrm{Pb}$ (II) ions from synthetic aqueous solution. However, it is recommended for in-depth analysis and further studies to know its application behavior in real industrial wastewater.

\section{Data Availability}

Data are available from the corresponding author upon request.

\section{Conflicts of Interest}

The authors have no conflicts of interest.

\section{Acknowledgments}

The authors would like to thank Ethiopian Road Authority for financial support.

\section{References}

[1] H. M. Zwain, M. Vakili, and I. Dahlan, "Waste material adsorbents for zinc removal from wastewater: a comprehensive review," International Journal of Chemical Engineering, vol. 2014, Article ID 347912, 13 pages, 2014.

[2] M. R. Awual, "Assessing of lead(III) capturing from contaminated wastewater using ligand doped conjugate adsorbent," Chemical Engineering Journal, vol. 289, pp. 65-73, 2016.

[3] M. R. Awual, "An efficient composite material for selective lead(II) monitoring and removal from wastewater," Journal of Environmental Chemical Engineering, vol. 7, no. 3, Article ID 103087, 2019.

[4] M. R. Awual and M. M. Hasan, "Novel conjugate adsorbent for visual detection and removal of toxic lead(II) ions from water," Microporous and Mesoporous Materials, vol. 196, pp. 261-269, 2014.

[5] L. Jin and R. Bai, "Mechanisms of lead adsorption on chitosan/PVA hydrogel beads," Langmuir, vol. 18, no. 25, pp. 9765-9770, 2002.

[6] D. W. O'Connell, C. Birkinshaw, and T. F. O’Dwyer, "Heavy metal adsorbents prepared from the modification of cellulose: a review," Bioresource Technology, vol. 99, no. 15, pp. 6709-6724, 2008.

[7] S. M. Beyan, S. V. Prabhu, T. T. Sissay, and A. A. Getahun, "Sugarcane bagasse based activated carbon preparation and its adsorption efficacy on removal of BOD and COD from textile effluents: RSM based modeling, optimization and kinetic aspects," Bioresource Technology Reports, vol. 14, Article ID 100664, 2021.

[8] K. Embaye, "The indigenous bamboo forests of Ethiopia: an overview," AMBIO: A Journal of the Human Environment, vol. 29, no. 8, pp. 518-521, 2000.

[9] J. Lin, S. Gupta, T. Loos, and R. Birner, "Opportunities and challenges in the Ethiopian bamboo sector: a market analysis of the bamboo-based value web," Sustainability, vol. 11, no. 6, p. 1644, 2019.

[10] S. Tadesse and D. Ambo, "Removal of basic dye from aqueous medium using activated carbon from Erythrina brucei, Arundinaria alpina and manihot esculenta," Food Science and Quality Management, vol. 86, pp. 19-27, 2019.

[11] K. Ukanwa, K. Patchigolla, R. Sakrabani, E. Anthony, and S. Mandavgane, "A review of chemicals to produce activated carbon from agricultural waste biomass," Sustainability, vol. 11, no. 22, pp. 6204-6235, 2019.

[12] Y. Alhamed, "Activated carbon from dates' stone by $\mathrm{ZnCl} 2$ activation," Journal of King Abdulaziz University-Engineering Sciences, vol. 17, no. 2, pp. 75-98, 2006.

[13] ASTM D2866-11, Standard Test Method for Total Ash Content of Activated Carbon, ASTM International, West Conshohocken, PA, USA, 2018, http://www.astm.org.

[14] ASTM D5832-98, Standard Test Method for Volatile Matter Content of Activated Carbon Samples, ASTM International, West Conshohocken, PA, USA, 2014, http://www.astm.org.

[15] ASTM D2854-09, Standard Test Method for Apparent Density of Activated Carbon, ASTM International, West Conshohocken, PA, USA, 2019, http://www.astm.org.

[16] ASTM D2867-17, Standard Test Methods for Moisture in Activated Carbon, ASTM International, West Conshohocken, PA, USA, 2017, http://www.astm.org.

[17] M. R. Awual and M. M. Hasan, "A ligand based innovative composite material for selective lead(II) capturing from wastewater," Journal of Molecular Liquids, vol. 294, Article ID 111679, 2019.

[18] ASTM E70-19, Standard Test Method for $p H$ of Aqueous Solutions With the Glass Electrode, ASTM International, West Conshohocken, PA, USA, 2019, http://www.astm.org.

[19] ASTM D888-18, Standard Test Methods for Dissolved Oxygen in Water, ASTM International, West Conshohocken, PA, USA, 2018, http://www.astm.org.

[20] M. Ahmedna, "Granular activated carbons from agricultural by-products: preparation, properties, and application in cane sugar refining," in LSU Agricultural Experiment Station Reports, LSU AG Center, Baton Rauge, LA, USA, 2000, http://digitalcommons.lsu.edu/agexp/456.

[21] P.-H. Huang, J.-W. Jhan, Y.-M. Cheng, and H.-H. Cheng, "Effects of carbonization parameters of moso-bamboo-based porous charcoal on capturing carbon dioxide," The Scientific World Journal, vol. 2014, Article ID 937867, 8 pages, 2014.

[22] B. Prakashkumar, K. Shivakamy, L. Miranda, and M. Velan, "Preparation of steam activated carbon from rubberwood sawdust (Hevea brasiliensis) and its adsorption kinetics," Journal of Hazardous Materials, vol. 136, no. 3, pp. 922-929, 2006.

[23] F. T. Ademiluyi and E. O. David-West, "Effect of chemical activation on the adsorption of heavy metals using activated carbons from waste materials," ISRN Chemical Engineering, vol. 2012, Article ID 674209, 5 pages, 2012.

[24] K. L. Wasewar, M. Atif, B. Prasad, and I. M. Mishra, “Adsorption of zinc using tea factory waste: kinetics, equilibrium and thermodynamics," CLEAN-Soil, Air, Water, vol. 36, no. 3, pp. 320-329, 2008.

[25] H. Xia, J. Wu, C. Srinivasakannan, J. Peng, and L. Zhang, "Effect of activating agent on the preparation of bamboobased high surface area activated carbon by Microwave heating," High Temperature Materials and Processes, vol. 35, no. 6, pp. 535-541, 2016.

[26] T. Dula, K. Siraj, and S. A. Kitte, "Adsorption of hexavalent chromium from aqueous solution using chemically activated carbon prepared from locally available waste of bamboo (oxytenanthera abyssinica)," ISRN Environmental Chemistry, vol. 2014, Article ID 438245, 9 pages, 2014.

[27] W. Kidus Tekleab, S. M. Beyan, S. Balakrishnan, and H. Admassu, "Chicken feathers based Keratin extraction process data analysis using response surface-box-Behnken design method and characterization of keratin product," Current Applied Science and Technology, vol. 20, no. 2, pp. 163-177, 2020. 
[28] S. Odoemelam, F. Onwu, S. Uchechukwu, and M. Chinedu, "Adsorption isotherm studies of $\mathrm{Cd}(\mathrm{ll})$ and $\mathrm{Pb}(\mathrm{ll})$ ions from aqueous solutions by bamboo-based activated charcoal and bamboo dust," American Chemical Science Journal, vol. 5, no. 3, pp. 253-269, 2015.

[29] Y. Gao, Q. Yue, B. Gao, and A. Li, "Insight into activated carbon from different kinds of chemical activating agents: a review," Science of the Total Environment, vol. 746, Article ID 141094, 2020.

[30] Y. Wang, X. Wang, X. Wang et al., "Adsorption of $\mathrm{Pb}$ (II) from aqueous solution to Ni-doped bamboo charcoal," Journal of Industrial and Engineering Chemistry, vol. 19, no. 1, pp. 353-359, 2013.

[31] M. R. Awual, "Novel conjugated hybrid material for efficient lead(II) capturing from contaminated wastewater," Materials Science and Engineering: C, vol. 101, pp. 686-695, 2019.

[32] M. R. Awual, A. Islam, M. M. Hasan et al., "Introducing an alternate conjugated material for enhanced lead(II) capturing from wastewater," Journal of Cleaner Production, vol. 224, pp. 920-929, 2019.

[33] V. Godoy, G. Blázquez, M. Calero, L. Quesada, and M. A. Martín-Lara, "The potential of microplastics as carriers of metals," Environmental Pollution, vol. 255, Article ID 113363, 2019.

[34] M. R. Awual, "Innovative composite material for efficient and highly selective $\mathrm{Pb}(\mathrm{II})$ ion capturing from wastewater," Journal of Molecular Liquids, vol. 284, pp. 502-510, 2019.

[35] W. Zhang, Y. An, S. Li et al., "Enhanced heavy metal removal from an aqueous environment using an eco-friendly and sustainable adsorbent," Scientific Reports, vol. 10, no. 1, Article ID 16453, 2020.

[36] F. Y. Wang, H. Wang, and J. W. Ma, “Adsorption of cadmium (II) ions from aqueous solution by a new low-cost adsorbentBamboo charcoal," Journal of Hazardous Materials, vol. 177, no. 1-3, pp. 300-306, 2010.

[37] M. Nur-E-Alam, M. Abu Sayid Mia, F. Ahmad, and M. Mafizur Rahman, "Adsorption of chromium (Cr) from tannery wastewater using low-cost spent tea leaves adsorbent," Applied Water Science, vol. 8, no. 5, p. 129, 2018.

[38] Y.-J. Zhang, J.-L. Ou, Z.-K. Duan, Z.-J. Xing, and Y. Wang, "Adsorption of $\mathrm{Cr}(\mathrm{VI})$ on bamboo bark-based activated carbon in the absence and presence of humic acid," Colloids and Surfaces A: Physicochemical and Engineering Aspects, vol. 481, pp. 108-116, 2015. 